\title{
Estudo dos métodos de remoção dos hábitos nocivos a oclusão dentária na odontopediatria
}

\author{
Cristhiane Olívia Ferreira do Amaral $^{1}$, Juliana Berti Mussoline ${ }^{2}$, Ruth Oliveira da Silva ${ }^{3}$ \\ ${ }^{1}$ Docente e ${ }^{3}$ acadêmica do Curso de Odontologia da UNOESTE, ${ }^{2}$ Cirurgiã dentista, Presidente Prudente, SP. crismaral@unoeste.br
}

\section{Resumo}

O presente trabalho teve por objetivo verificar a época de início e remoção dos hábitos nocivos de sucção nos pacientes pediátricos, analisar qual o hábito nocivo de sucção com maior freqüência e com maior dificuldade de remoção, investigar quais as técnicas usadas pelas mães das crianças que tinham os hábitos e conseguiram removê-los. Foi realizada uma entrevista quali-quantitativa em um formulário estruturado com as mães, cujo critério de inclusão foi seus filhos serem pacientes da Clínica de Odontopediatria da Faculdade de Odontologia da Unoeste e que já apresentavam hábitos de sucção nocivos como dedo, chupeta e mamadeira. Outro critério de inclusão foi à assinatura de um termo de consentimento livre e esclarecido pela mãe que participou da pesquisa. Analisando os dados obtidos foi observado que $72 \%$ das mães inserem hábitos nocivos a oclusão dos seus filhos de 0 a 6 meses de idade, sendo o hábito de sucção mais freqüente a chupeta e o de maior dificuldade de remoção a sucção de dedo. Quanto à remoção dos hábitos, observa-se uma grande diversidade de métodos, sendo que, de modo geral, a aceitação da criança ao tratamento é fundamental para o sucesso do mesmo e para prevenir ou minimizar os possíveis efeitos psicológicos envolvidos.

Palavras-chave: métodos de remoção, sucção, hábitos nocivos, odontopediatria.

\section{Study of methods for removal of harmful habits in a dental occlusion in pediatric dentistry}

\begin{abstract}
This study aimed to verify the time of onset and removal of harmful habits of suction in pediatric patients by an analysis of the harmful habit of sucking more frequently and with greater difficulty of removal, to investigate the techniques used by mothers of children who had habits and were able to remove them. We performed a qualitative and quantitative interview in a structured form with mothers whose inclusion criterion was their children are patients of the Clinic of Dentistry School of Dentistry Unoeste and have already made use of harmful sucking habits, such as finger, pacifier and bottle. Another inclusion criterion was the signing of an informed consent by the mother who participated in the research. Analyzing the data obtained it was observed that $72 \%$ of mothers fall into bad habits occlusion of their children from 0 to 6 months of age, and the habit of sucking a pacifier more frequent and more difficult to remove the suction finger. The removal of customs, there is a wide variety of methods, which, in general, the acceptance of the child when treatment is essential to its success and to prevent or minimize the possible psychological effects involved.
\end{abstract}

Keywords: methods of removal, suction, harmful habits, pediatric dentistry. 


\section{Introdução}

A sucção é um reflexo inato que pode ser desenvolvido pelo feto, ainda dentro do útero, durante a alimentação este reflexo visa à ingestão do leite materno. O hábito de sucção é fisiológico em todas as crianças do nascimento até cerca de dois anos de idade de acordo com a necessidade individual de sucção e do desenvolvimento social da criança. Porém, quando o hábito ultrapassa a fase de sucção prolongando-se durante a fase de mastigação e no período da dentição mista, pode provocar mudanças no crescimento e desenvolvimento da face e nas dentições.

Neste momento, o hábito torna-se nocivo e deve ser eliminado, porém deve-se considerar que a eliminação brusca ou traumática pode ter uma conotação negativa e originar até um sentimento de culpa ou de inferioridade na criança, inclusive levando ao desenvolvimento de um novo hábito (VIEIRA, 2006).

Hábito é a repetição de um ato que com o tempo pode levar a conseqüências indesejáveis. Podem ser classificados como normais ou indesejáveis. Os normais são aqueles que contribuem para uma oclusão normal favorecendo o crescimento facial, sem desvios. Quando as funções bucais constituírem fatores etiológicos alterando a oclusão do padrão normal de crescimento, são considerados hábitos bucais indesejáveis (BENGTSON, 2006).

A amamentação no peito é muito importante, principalmente nos primeiros seis meses de vida, tanto do ponto de vista nutricional e imunológico, como no desenvolvimento da função e oclusão das crianças (GAMA et al., 1997; MODESTO et al., 1999). As funções realizadas através da amamentação promovem estímulos neurais adequados ao crescimento ósseo e muscular para prevenir as maloclusões por hipodesenvolvimento (QUELUZ; GIMENEZ, 2000).
A amamentação artificial, no entanto, não exige esforços, nem satisfaz as necessidades de sucção da criança, pois se trata de um mecanismo muito diferente da sucção no seio, fazendo com que a criança não desenvolva normalmente a musculatura e alguns componentes ósseos de sua face (ALMEIDA et al., 2000).

Crianças com menor tempo de aleitamento materno desenvolvem, com maior freqüência, hábitos bucais deletérios, possuindo um risco relativo sete vezes superiores com relação àquelas aleitadas no seio por um período de, no mínimo, seis meses. Crianças aleitadas com mamadeira por mais de um ano apresentam quase dez vezes mais risco de apresentarem hábitos bucais viciosos do que aquelas que nunca utilizaram essa forma de aleitamento. Os hábitos bucais deletérios estão fortemente associados às maloclusões (SERRA-NEGRA et al., 1997).

Cientes da dificuldade que os pais têm em remover a mamadeira e o efeito nocivo que ela causa, uma maneira usada para conseguir seria a diluição do conteúdo cada vez mais em água deixando-a menos saborosa, oferecendo como recompensa o líquido na sua consistência normal, em um copinho. A chupeta também é um dos maiores problemas que as mães tem em relação à remoção do hábito. Sua continuidade ao longo do crescimento age como grande causadora de dentes fora de posição como, de mordida aberta, de interposição de língua. Este hábito não deveria ser usado, mas quando já está instalado, a preferência deve ser por bicos ortodônticos, pois se assemelha ao seio materno.

A chupeta deve ser tirada aos dois a dois anos e meio de idade. Evite amarrar lacinho ou correntinha na chupeta, pois será uma forma de estimular a criança a adquirir este vício. Uma maneira de remover este hábito é colocar algodão dentro da parte onde é feita a sucção, isso fará com que ela fique muito mais 
consistente e desagradável a sucção. A sua remoção logo que a criança adormecer é outra maneira de retirar o hábito lento e agradável (BENGTSON, 2006).

Já a sucção de dedo é comum, pois se vê que muitos bebês chupam o dedo no ventre materno mesmo antes de nascer. O desenvolvimento de sucção até uma fase da infância é normal e deve desaparecer entre 1 e 3 anos e meio de idade (DELASSUS, 2001).

As formas mais comuns de remoção são a aplicação de substância com sabor desagradável nos dedos de sucção, a troca pela chupeta com algodão na parte a ser succionada, o uso de esparadrapo, gaze nos dedos comuns a sucção e o uso de pijamas de manga longa que ultrapasse duas vezes o tamanho do braço da criança. Este hábito trará conseqüências estéticas e funcionais maiores que o do uso da chupeta quando os dentes decíduos começarem a erupcionar (CORRÊA, 2005).

O presente trabalho teve por objetivo verificar a época de início e remoção dos hábitos nocivos de sucção nos pacientes pediátricos, analisar qual o hábito nocivo de sucção com maior freqüência e com maior dificuldade de remoção, investigar quais as técnicas usadas pelas mães das crianças que tinham os hábitos e conseguiram removê-los.

\section{Métodos}

Este estudo foi realizado com mães, cujo critério de inclusão foi que as crianças realizassem acompanhamento odontológico na clínica de Odontopediatria da Faculdade de Odontologia da Unoeste, e que já apresentassem hábitos de sucção nocivos como dedo, chupeta, mamadeira, para que fossem avaliados os métodos de remoção dos Hábitos nocivos a oclusão de seus filhos. Foi realizado 0 experimento com um total de 100 mães com idades variadas (18 a 42 anos) que levavam seus filhos para tratamento odontológico na clínica de Odontopediatria. As crianças foram de ambos os sexos com idade entre 3 e 12 anos, sendo 55 meninos e 45 meninas. Após a aprovação pelo Comitê de Ética em Pesquisa da Unoeste, as mães preencheram um termo de consentimento livre e esclarecido. Foi preenchido um formulário composto por uma ficha anamnética com questões quantitativas e qualitativas, sobre os hábitos nocivos dos pacientes, como sucção de dedo chupeta e mamadeira e as formas que elas conseguiram removê-los. Os dados obtidos por meio da entrevista e anotados no formulário padronizado foram tabulados e submetidos a analise estatística descritiva para apresentação de valores relativos.

\section{Resultados}

A prevalência de hábitos nocivos à saúde bucal foi de 54\% dos 100 pacientes avaliados, sendo que a maior freqüência encontrada foi no hábito de chupeta com 34\%, bem maior que o de sucção de dedo que foi de $10 \%$ e o de mamadeira 4\% (Figura 1).

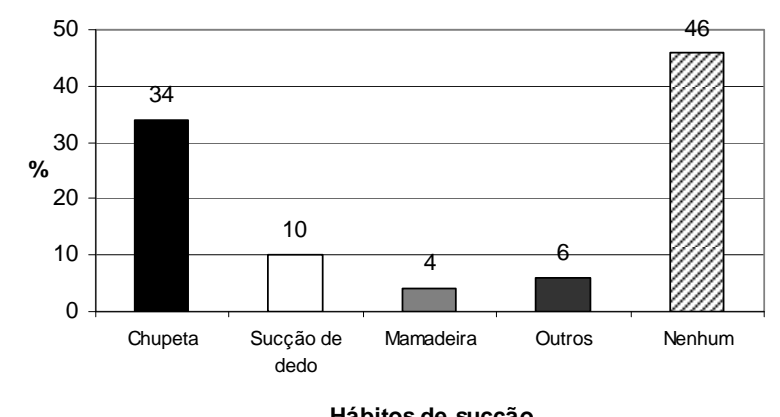

Figura 1. Sobre os hábitos de sucção do filho.

Das crianças com hábito de chupeta, 37\% delas iniciaram este vício de 0 a 3 meses e 20\% de 3 a 6 meses, enquanto que os hábitos de sucção de dedo e mamadeira foram em porcentagem menores: 11\% sucção de dedo e $2 \%$ mamadeira para a idade de 0 a 3 meses. $\mathrm{Na}$ idade de 3 a 6 meses a porcentagem foi de 0\% 
para a sucção de dedo e $2 \%$ para mamadeira

(Figura 2).

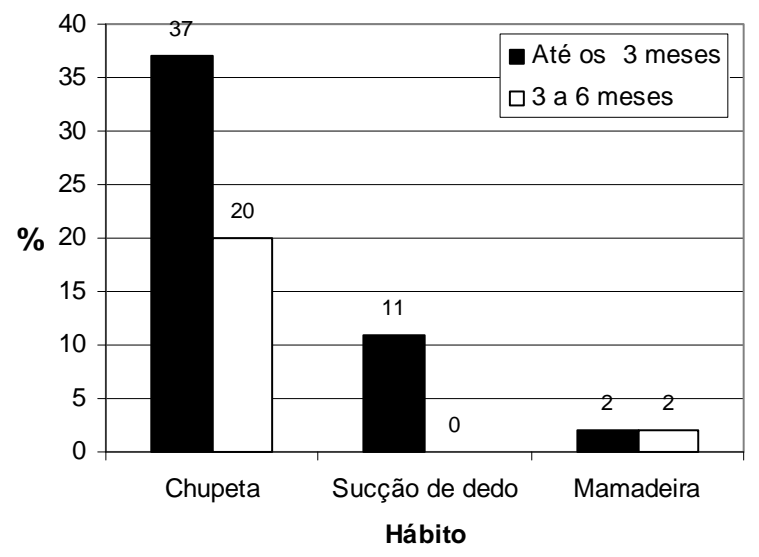

Figura 2. Sobre a idade em que começou o hábito do filho.

De acordo com a Figura 3, um número grande de crianças (90\%) que possuíam o hábito de sucção de dedo ainda o apresentava, não haviam conseguido parar, seguido pelo hábito da mamadeira 40\%, mas das crianças que possuíam o vício da chupeta apenas $12 \%$ das entrevistadas ainda permaneciam com o hábito.

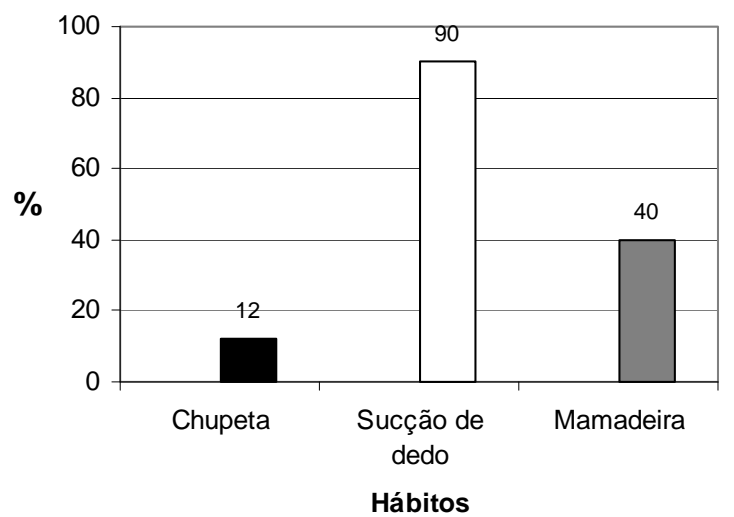

Figura 3. Sobre os hábitos que não cessaram.

Em relação à intensidade dos hábitos nocivos, as crianças os praticavam mais durante o sono com a quantidade de $42 \%$ dos pacientes, seguido pelo dia todo com o resultado de 33\% e 11\% praticavam apenas quando assistiam TV, como demonstrado na Figura 4.

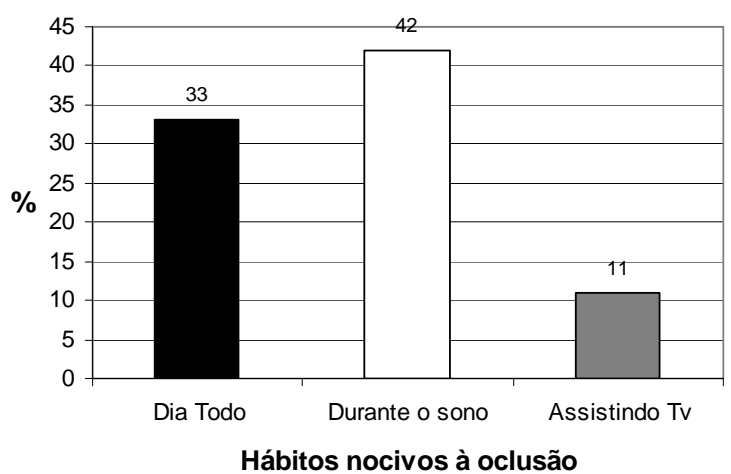

Figura 4. Sobre o período do hábito nocivo do filho.

Sobre a dificuldade de remoção do hábito, as mães que os pacientes possuíam o hábito de sucção de dedo (90\%) e mamadeira (75\%) acharam que estes hábitos eram de difícil remoção, por outro lado os que tinham vício da chupeta apenas 18\% das mães acharam que a chupeta era um hábito de difícil a remoção (Figura 5).

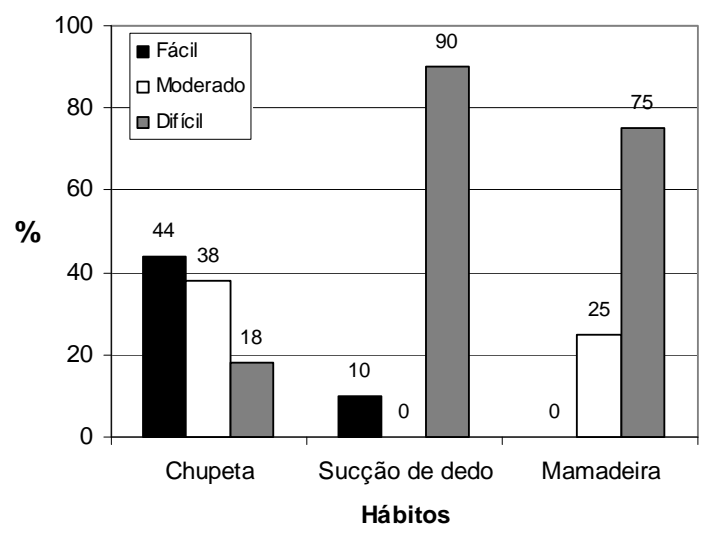

Figura 5. Sobre a dificuldade em remover o hábito do filho.

As mães pesquisadas deram diferentes exemplos durante a entrevista de como conseguiram que seus filhos deixassem os hábitos deletérios a sua oclusão, em resposta a pergunta descrita na tabela 1. 
Tabela 1. Sobre os métodos que a mãe usou para que seu filho deixasse o hábito nocivo.

\begin{tabular}{|c|c|c|c|c|c|}
\hline Método 1 & Método 2 & Método 3 & Método 4 & Método 5 & \\
\hline $\begin{array}{l}\text { 1. Colocar } \\
\text { produtos com } \\
\text { sabores } \\
\text { desagradáveis no } \\
\text { local da sucção }\end{array}$ & $\begin{array}{l}\text { 2. Reforçar o } \\
\text { efeito estético }\end{array}$ & $\begin{array}{l}\text { 3. Mostrar falta } \\
\text { de higiene }\end{array}$ & $\begin{array}{l}\text { 4. Trocar por algo } \\
\text { que a criança } \\
\text { queira muito }\end{array}$ & $\begin{array}{l}\text { 5. Retirar de } \\
\text { acesso o hábito }\end{array}$ & Outros \\
\hline $\begin{array}{l}\text { Pimenta, para } \\
\text { arder e criança } \\
\text { associar a } \\
\text { chupeta }\end{array}$ & $\begin{array}{l}\text { Todos reforçaram } \\
\text { que fica feio com } \\
\text { o hábito }\end{array}$ & $\begin{array}{l}\text { Quando a } \\
\text { chupeta ficou } \\
\text { velha a mãe } \\
\text { furou para sentir } \\
\text { o mau cheiro }\end{array}$ & $\begin{array}{l}\text { A mãe disse para } \\
\text { dar a chupeta para } \\
\text { o papai Noel que } \\
\text { ela ganharia um } \\
\text { presente }\end{array}$ & $\begin{array}{l}\text { A mãe não } \\
\text { oferecia a } \\
\text { chupeta e } \\
\text { reforçava a } \\
\text { necessidade de } \\
\text { parar }\end{array}$ & $\begin{array}{l}\text { Parou quando } \\
\text { teve } \\
\text { estomatite, } \\
\text { dor na boca } \\
\text { ao succionar }\end{array}$ \\
\hline $\begin{array}{l}\text { Boldo, pois esta } \\
\text { erva é muito } \\
\text { amarga }\end{array}$ & $\begin{array}{l}\text { A mãe colocou } \\
\text { medo falando que } \\
\text { o dente iria ficar } \\
\text { torto e feio }\end{array}$ & $\begin{array}{l}\text { A chupeta ficou } \\
\text { velha e a mãe } \\
\text { falou que jogou } \\
\text { no vaso do } \\
\text { banheiro e a } \\
\text { criança não quis } \\
\text { mais }\end{array}$ & $\begin{array}{l}\text { Troca por presente } \\
\text { do papai Noel, } \\
\text { mas depois voltou } \\
\text { a chupar, jogou no } \\
\text { lixo em troca de } \\
\text { outro presente }\end{array}$ & $\begin{array}{l}\text { A mãe escondeu } \\
\text { a chupeta }\end{array}$ & $\begin{array}{l}\text { Colocou } \\
\text { expansor para } \\
\text { descruzar a } \\
\text { mordida e } \\
\text { parou }\end{array}$ \\
\hline $\begin{array}{l}\text { Colocou fezes de } \\
\text { gato na frente da } \\
\text { criança e jogou } \\
\text { fora }\end{array}$ & $\begin{array}{l}\text { Mostrava sempre } \\
\text { alguém na TV } \\
\text { que era bem feio }\end{array}$ & $\begin{array}{l}\text { Jogou a chupeta } \\
\text { para o porquinho, } \\
\text { para a criança } \\
\text { ver ficar suja }\end{array}$ & $\begin{array}{l}\text { Trocou por uma } \\
\text { boneca }\end{array}$ & $\begin{array}{l}\text { A criança perdeu } \\
\text { e a mãe não } \\
\text { comprou mais }\end{array}$ & $\begin{array}{l}\text { Chupava } \\
\text { chupeta } \\
\text { ortopédica, } \\
\text { mudança de } \\
\text { bico e não se } \\
\text { adaptou }\end{array}$ \\
\hline $\begin{array}{l}\text { Mel com sal, a } \\
\text { criança achou o } \\
\text { gosto horrível e } \\
\text { parou }\end{array}$ & $\begin{array}{l}\text { Mostrava no } \\
\text { espelho e fotos } \\
\text { os dentes que } \\
\text { estavam feios e } \\
\text { tortos }\end{array}$ & $\begin{array}{l}\text { Mostrar o bico } \\
\text { preto e fala que é } \\
\text { bactéria }\end{array}$ & $\begin{array}{l}\text { Trocou por um } \\
\text { skate }\end{array}$ & $\begin{array}{l}\text { Pediu para jogar } \\
\text { que compraria } \\
\text { outra }\end{array}$ & $\begin{array}{l}\text { Competiu com } \\
\text { oprimo quem } \\
\text { era mais forte } \\
\text { e parou } \\
\text { primeiro }\end{array}$ \\
\hline
\end{tabular}

\section{Discussão}

De um total de 100 questionários analisados na faixa etária de 3 a 12 anos, 54\% das crianças estudadas possuem algum hábito nocivo. O hábito mais prevalente nesse estudo foi a chupeta entre os que possuíam algum hábito nocivo, em concordância com o trabalho de Crato (2004) que chegaram ao resultado de $52 \%$ de prevalência de hábito nocivo. Segundo Vieira (2006), o hábito de sucção é fisiológico em todas as crianças, do nascimento até cerca de 2 anos de idade. Porém, quando o hábito ultrapassa essa fase e prolonga-se a fase de mastigação e no período da dentição mista tornase nocivo e deve ser eliminado.

Percebe-se com esses resultados que a maioria (50\%) das mães inserem os hábitos nocivos a oclusão de seus filhos de 0 a 3 meses, seguido de 3 a 6 meses (22,2\%). O hábito mais prevalente neste estudo foi a chupeta (63\%) e foi maior quando comparado ao estudo de Crato, (2004), que em seu resultado o encontrado foi de
23\%. O hábito mais fácil de ser removido é a chupeta, pois $53 \%$ foram removidos antes dos 4 anos de idade, enquanto o hábito de sucção de dedo é o mais difícil e demorado de ser eliminado, visto que $90 \%$ das crianças estudadas não removeram o hábito, apesar de terem mais de 8 anos. Toledo e Bezerra (1996) estabeleceram duas causas de sucção de polegar: criança que foi frustrada nos primeiros meses com sucção insatisfatória ou criança que não teve suficiente atenção maternal com outra necessidade de estímulo.

Quando o hábito tem origem numa idade precoce com intensidade e freqüências altas, não somente os dentes e o processo alveolar são atingidos, mas também o desenvolvimento do esqueleto facial pode ser desviado do seu curso normal (MOYERS, 1991).

Os resultados sobre freqüência e intensidade do hábito foram $33 \%$ das crianças praticavam o hábito o dia todo, $42 \%$ das crianças apenas quando dormiam e $11 \%$ quando 
assistiam TV. Barnett (1978) sugere colocar o paciente frente ao espelho e mostrar para ela como fica feio. Black (1990) menciona a autosugestão durante o sono e também uso de aparelhos de impedimento mecânico, colocar gaze, esparadrapo, se for dedo usar luvas, prender a manga da camisa, estabilizar de alguma forma o braço, passar produtos coloridos ou com gosto ruins, ridicularizar o hábito. Greenly (1982) substitui a sucção por pedaços de parafina, dormir com uma bandagem no braço e fita adesiva na ponta do dedo.

Em qualquer caso de tratamento de hábito bucal, há a necessidade de carinho, compreensão dos pais e motivação da criança além de prudência por parte do profissional e dos pais, pois existem muitos questionamentos sobre os métodos empregados e há possíveis efeitos indesejáveis (VIEIRA, 2006).

Concluiu-se neste estudo que 54\% das crianças estudadas possuem algum hábito nocivo, 72\% das mães inserem hábitos nocivos a oclusão dos seus filhos de 0 a 6 meses. 0 hábito nocivo de sucção mais freqüente é a chupeta (63\%) e a maioria das crianças que possuíam o hábito de chupar chupeta (88\%) já pararam com a prática. Já o hábito de maior dificuldade de remoção é o de sucção de dedo (90\%).

Pode-se averiguar que as técnicas usadas pelas mães são: colocar produtos com sabores desagradáveis no local da sucção, reforçar o efeito estético, mostrar a falta de higiene, trocar por algo que a criança queira muito, retirar de acesso o hábito. Os profissionais sempre devem ter prudência no momento de indicar formas terapêuticas de remoção do hábito.

\section{Referências}

Almeida RR, Almeida-Pedrin RR, Almeida MR, Garib DG, Almeida PCMR, Pinzan A. Etiologia das más oclusões - causas hereditárias e congênitas adquiridas gerais, locais e proximais. Revista Dental Press de Ortodontia e Ortopedia Facial 2000; 5(6):107-29.

Barnett EM. Terapia oclusal em Odontopediatria. Buenos Aires: Médica Panamericana, 1978.

Black B. Hábitos bucais nocivos. Revista da Sociedade Paulista de Ortodontia 1990; 23(2):404.

Bengtson AL. Orientação aos pais sobre hábitos bucais, Revista de odontologia [periódico eletrônico] 2006 [citado em 2006 maio 10]; 1(1) Disponível em: http://www.unimes.br/academico/odontoipediatria Corrêa MSNP. Odontopediatria na Primeira Infância. São Paulo: Ed. Santos, 2005.

Delassus JM. Le génie du foetus vie prénatale et origine de l'homme. Paris: Dunod, 2001.

Crato AL. Hábitos orais deletérios e relação com aspectos comportamentais e psicológicos de crianças de creches públicas de Belo Horizonte In: Anais do $7^{0}$ Encontro de Extensão da Universidade Federal de Minas Gerais, 2004; Belo Horizonte, Brasil. p.7

Gama FVA, Solviero VM, Bastos EPS, Souza IPR. Amamentação e desenvolvimento: função e oclusão. Jornal Brasileiro de Ortodontia e Ortopedia Facial 1997; 2(11):17-20.

Greenly L. Suggestions for combatting digit sucking. The international Journal of Orofacial Myology, 1982; 8(3):22-3.

Modesto A, Vieira AR, Camargo MCF. Avaliação do uso e das características das chupetas utilizadas por crianças no município do Rio de Janeiro. Jornal Brasileiro de Odontopediatria \& Odontologia do Bebe 1999; 2(10):11-9.

Moyers RE. Ortodontia. Rio de Janeiro: Guanabara Koogan, 1991. 
Queluz DP, Gimenez CMM. Aleitamento e hábitos deletérios relacionados à oclusão. Revista Paulista de Odontologia 2000; 22(6):1620.

Serra-Negra JMC, Pordeus IA, Rocha JR, Ferreira J. Estudo da associação entre aleitamento, hábitos bucais e maloclusões. Revista de Odontologia da Universidade de São Paulo 1997; 11(2): 26-30.

Toledo OA, Bezerra ACB. Hábitos bucais indesejáveis. In: Toldo AO. Odontopediatria fundamentos para a prática clínica. 2.ed. São Paulo: Premier; 1996. p.319-25.

Vieira AMGS, Hábitos de sucção do polegar: como descontinuá-lo? Revista de Odontologia [periódico eletrônico] 2006 [citado em 2006 maio 11]; 15(1). Disponível em: http://www.odontolgia.com.br/artigos.asp 